\title{
Improved Optimal Operation Planning Method Based on Tabu Search for Residential PEFC-CGS Considering Ramping Rate
}

\author{
Satoshi Nomoto, Teruhisa Kumano \\ Department of Electrical Engineering, Meiji University, Kawasaki, Japan \\ Email: ce41079@meiji.ac.jp
}

Received February 2015

\begin{abstract}
This paper proposes an improved optimal operation planning method for residential PEFC-CGS (Polymer Electrolyte Fuel CellCo-Generation System). Residential PEFC-CGS has recently been gathering attention as one of the distributed power sources with high efficiency and low environmental impacts. Previous research pointed out that the output variations of PEFC adversely affect the durability. It can be surmised that smaller output variations will be desired to extend durability years. However, in this field, ramping rate have not been sufficiently considered. For local search and tabu search, ramping rate constraint makes our operation planning difficult because it restricts the search for feasible neighborhood solutions. Therefore, the authors proposed a method to deal with typical and harsher ramping rate constraints in comparison with conventional methods. There are two key points for the improvement. One is the reinforcement of the search along the output power axis; the other is to make use of the strategy of tabu search which avoids the local optimal solutions. The simulation results show the effectiveness of the proposed method in the daily operation planning. Furthermore, in the case using typical ramping rate parameter, it is confirmed that tabu search doesn't contribute the reduction of daily operational cost due to the above stated restriction of the search area.
\end{abstract}

\section{Keywords}

Distributed Generation, PEFC-CGS, Local Search, Tabu Search, Operation Planning, Ramping Rate

\section{Introduction}

Residential PEFC-CGS has been on sale in Japan since 2009 as one of the distributed power supplies with high efficiency and low environmental impact. According to [1], in 2013 the shipment volume of PEFC-CGS approximately reached 250,000 [kW] in Japan, and in 2014 [2] shows that it started to be on sale in Germany. It can be estimated that PEFC-CGS will be spreading out other countries in the future. For these reasons, the oper- 
ation planning for residential PEFC-CGS becomes more important in order to maximize the introduction effects. The operation planning method for fuel cell CGS has been already researched in the existing studies such as [3]-[5]. However, they disregarded ramping rate constraint in the operation planning. In addition, [6] pointed out that the output variations of PEFC adversely affect the durability. Accordingly, it can be considered that smaller output variations will be desired to extend durability years. Consequently, it is essential for the optimal operation planning to consider and discuss the ramping rate constraint.

For easily considering the ramping rate constraint and the efficacy of tabu search, in this paper, we apply tabu search to the operation planning considering ramping rate for residential PEFC-CGS, and improve it for avoiding the trap into local optimal solutions. Moreover, we studied how ramping rate constraint affects the operation planning with the 2 simulation cases; harsh ramping rate and the standard ramping rate are applied in the respective cases.

\section{Problem Formulation}

\subsection{Assumed Model}

Assumed PEFC-CGS model and its specifications are shown in Figure 1 and Table 1. The output of PEFC nonlinearly affects its electrical and heat efficiencies. Therefore, we introduce the electricity and heat efficiency shown in Figure 2. The efficiency and the specifications are assumed based on [7]. According to [7], they are not the best ones in Japanese top-runner program, but reasonably selected considering aged deterioration. In addition, the adequacy of the specifications is calculated and evaluated in [8]. Table 2 describes electrical power and gas charge. Table 3 displays the temperature of supply water used in calculation.

\subsection{Formulation}

In this paper, the operation planning problem for residential PEFC-CGS is formulated as follows:

\section{Objective Function:}

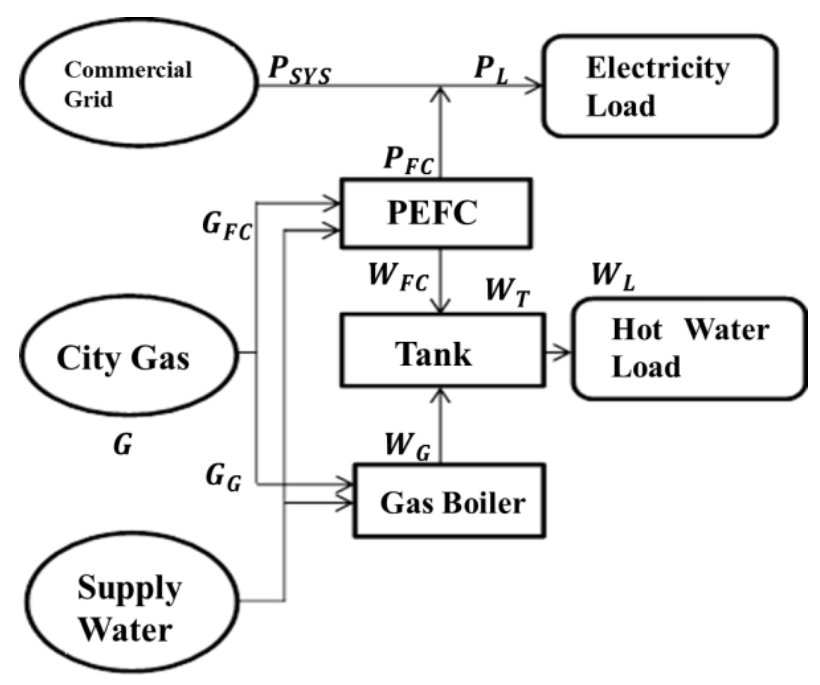

Figure 1. Assumed model.

Table 1. Specifications of assumed system [7].

\begin{tabular}{cccc}
\hline Capacity of Storage Tank & $200[\mathrm{~L}]$ & Electrical Efficiency (Max) & $36[\%]$ \\
Hot Water Temperature & $70\left[{ }^{\circ} \mathrm{C}\right]$ & Heat Efficiency (Max) & $45[\%]$ \\
Max Power & $700[\mathrm{~W}]$ & Heat Efficiency (Gas Boiler) & $82[\%]$ \\
Minimum Power & $250[\mathrm{~W}]$ & Start-up Loss $\left(P_{\text {Loss }}\right)$ & $0.5[\mathrm{kWh}]$ \\
Initial Storage Water & $50[\mathrm{~L}]$ & & \\
\hline
\end{tabular}




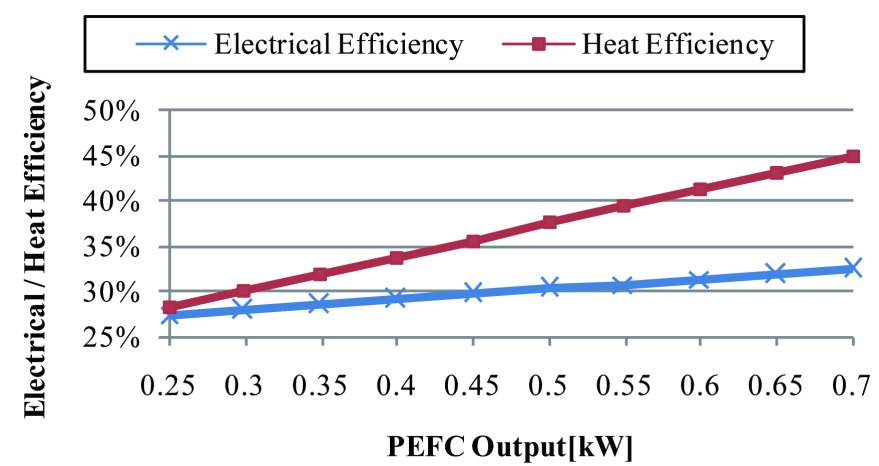

Figure 2. Electrical and heat efficiency [7].

Table 2. Electrical power and gas charge and conversion factors of $\mathrm{CO}_{2}$ emission.

\begin{tabular}{|c|c|c|c|}
\hline & \multicolumn{2}{|c|}{ Electric Power } & City Gas \\
\hline Rate & $\begin{array}{l}\text { 11:00pm } \sim 7: 00 \mathrm{am} \\
\text { 1:00pm } \sim 4: 00 \mathrm{pm} \\
\text { Other Times }\end{array}$ & $\begin{array}{l}12 \text { [yen/kWh] } \\
53 \text { [yen/kWh] (Summer) } \\
28 \text { [yen/kWh] }\end{array}$ & $44\left[\right.$ yen $\left./ \mathrm{m}^{3}\right]$ \\
\hline Conversion Factor of $\mathrm{CO}_{2}$ Emission & 0.5 & $\mathrm{~kg} / \mathrm{kWh}][9]$ & $\begin{array}{l}0.689 \text { [kg/kWh] (PEFC) [10] } \\
2.366[\mathrm{~kg} / \mathrm{kWh}] \text { (Gas Boiler) [11] }\end{array}$ \\
\hline
\end{tabular}

Table 3. Temperature of supply water (Tokyo) [12].

\begin{tabular}{|c|c|c|c|}
\hline & Summer (Aug.) & Middle Season (Apr.) & Winter (Jan.) \\
\hline Temperature $\left[{ }^{\circ} \mathrm{C}\right]$ & 27.3 & 13.0 & 6.7 \\
\hline
\end{tabular}

\section{Constraints:}

$$
\begin{aligned}
& W_{T t}=W_{T t-1}-W_{L t}+W_{\mathrm{FC} t}+W_{G t} \\
& P_{D t}+P_{\mathrm{Loss}}=P_{\mathrm{FC} t}+P_{\mathrm{SYSt}} \\
& G_{t}=G_{\mathrm{FC} t}+G_{G t} \\
& 0=W_{T t} \leq W_{T \mathrm{MAX}} \\
& P_{\mathrm{FCMIN}} \leq P_{\mathrm{FCt}} \leq P_{\mathrm{FCMAX}} \\
& -\Delta P_{\mathrm{DOWN}} \leq P_{\mathrm{FCt}}-P_{\mathrm{FCt}-1} \leq \Delta P_{\mathrm{UP}}
\end{aligned}
$$

where,

$f$ : Daily Operational Cost (DOC) [yen],

$\alpha$ : Carbon tax $(=0.289)$ [12] [yen $/ \mathrm{kg}^{*} \mathrm{CO}_{2}$ ],

$T$ : The number of time frames (48 frames, a day, 24 hours are divided by 0.5 hour),

$\operatorname{COST}_{p t}$ : Electricitycharge at a time $t[\mathrm{yen} / \mathrm{kWh}$,

$\operatorname{COST}_{G t}$ : Gas charge at a time $t\left[\right.$ yen $\left./ \mathrm{m}^{3}\right]$,

$P_{\mathrm{FCt}}$ : Electrical energy from PEFC obtaineduntil time $t$ [kWh],

$P_{\text {SYSt }}$ : Electrical energy from commercial grid obtained until time $t$ [kWh],

$P_{\text {Loss }}$ : Electrical energy of start-up loss [kWh],

$P_{D t}$ : Electricity demand at a time $t[\mathrm{kWh}$,

$K_{\mathrm{FC}}$ : Conversion factor of $\mathrm{CO}_{2}$ emission (PEFC) [kg* $\mathrm{CO}_{2} / \mathrm{kWh}$, 
$K_{E}$ : Conversion factor of $\mathrm{CO}_{2}$ emission (Commercial grid) $\left[\mathrm{kg} * \mathrm{CO}_{2} / \mathrm{kWh}\right.$,

$K_{G}$ : Conversion factor of $\mathrm{CO}_{2}$ emission (gas boiler) $\left[\mathrm{kg}^{*} \mathrm{CO}_{2} / \mathrm{kWh}\right]$,

$W_{L t}:$ Hot water load at a time $t[\mathrm{~L}]$,

$W_{T t}$ : Amount of hot water in the tank at a time $t[\mathrm{~L}]$,

$W_{\mathrm{FCt}}$ : Amount of hot water obtained by PEFC at a time $t[\mathrm{~L}]$,

$W_{G t}$ : Amount of hot water obtained by gas boiler at a time $t[\mathrm{~L}]$,

$G_{t}$ : Amount of used gas at a time $t\left[\mathrm{~m}^{3}\right]$,

$G_{\mathrm{FCt}}$ : Amount of gas used by PEFC at a time $t\left[\mathrm{~m}^{3}\right]$,

$G_{G t}$ : Amount of gas used by gas boiler at a time $t\left[\mathrm{~m}^{3}\right]$,

$\Delta P_{\mathrm{UP}}$ : Max ramping rate (increase) $[\mathrm{kW} / 0.5 \mathrm{~h}]$,

$\Delta P_{\text {Down }}$ : Max ramping rate (decrease) $[\mathrm{kW} / 0.5 \mathrm{~h}]$.

Objective function (1) aims to minimize daily operation cost and it takes into account electricity, gas charge, and carbon tax calculated by the $\mathrm{CO}_{2}$ emission. Equation (2), (3), and (4) represents the equality constraint concerning hot water, electricity and gas. In this problem, hot water supplied from PEFC or ancillary gas boiler. Moreover, start and stop are assumed once per a day so as to minimize start-up loss. Start-up loss is considered in Equation (3). Inequality (5) represents tank capacity constraint. Inequality (6) describes max/min output constraint for PEFC. Inequality (7) means the ramping rate constraint.

\section{Operation Planning Methods}

\subsection{Local Search (LS)}

Local search (LS) method is one of simple optimization methods, and also called hill-climbing method. At first, LS for daily operation planning creates neighborhood solutions from the initial operation plan. In this problem, the search can be divided into 2 directions, time axis, and output power axis. Therefore, the search process has two steps as follows:

Step 1: Create neighborhood solutions for start-stop time of PEFC. The types of "neighborhood" are classified into 9 patterns. The following is the candidate procedures to choose for creating neighborhood solutions concerning start-time and stop-time:

1) Keep start time or stop time

2) Move start time or stop time to the earlier time

3) Move start time or stop time to the later time

Step 2: Create neighborhood solutions along the axis of output from the feasible neighborhood solutions of Step 1. The types of "neighborhood" here are classified into 2 directions (increase or decrease) at each time

After 2 steps, the best solution is selected among the feasible neighborhood solutions, and it is regarded as next initial solution.

\subsection{Tabu Search (TS)}

Tabu Search (TS) [14] [15] is one of metaheuristic algorithms based on local search, and it was proposed by the analogy to human memory. The algorithm of tabu search introduces a kind of memory called tabu list into the local searchin order to avoid local optimal solutions. Tabu list has memories of the attribute of the search, and update serially. The search proceeds to the neighborhood solutions on the way except for the movements on tabu list, even if it is worse solution. Parameter tuning is one of the complicated problems in many metaheuristic algorithms. However, tabu search has only one parameter called tabu length, which means the capacity of memory. For this reason, tabu search has a great advantage which is ease of application in comparison to other metaheuristic techniques.

In this problem, the numbers of neighborhood solutions on output axis obviously tend to be created more than the number on time axis. Thus, local search on output axis is likely to be trapped into the local optimum solutions. In this paper, we have applied tabu search to the local search on output axis only in order to escape from local optimum solutions. Therefore, the direction of the search (increase or decrease) and the time are recorded on tabu list after the determination of the best solution. 


\subsection{Proposed Method (Modified TS, MTS)}

For local search and tabu search, it is important to guide the search to the proper direction. In the case of considering ramping rate, it can be considered that the search on time axis is restricted by ramping rate constraint. Therefore, we improved local search and tabu search to deal with this problem. The improvement is to restrict the search on time axis to reinforce the search on output axis. We call it modified tabu search (MTS). Figure 3 describes the flowchart of the proposed method (MTS). As shown in Figure 3, modified tabu search creates neighborhood solutions on time axis only one per $\mathrm{N}$, which is introduced parameter. In addition, we also used modified local search (MLS) in the simulation for the purpose of comparison.

\section{Simulation Conditions and Results}

Table 4 shows the summation of electricity demand and hot water demand in each season, which is determined based on [7]. The demands are assumed to be known in advance. According to [7], these demands are measured values. Reference [7] classifies hot water demand into 3 patterns, large, middle, and small on the basis of the summation. Accordingly, we follow their policy. In this paper, we assumed 2 cases of ramping rate constraint. One is harsh ramping rate; the other is standard one [7], and they are shown in Table 5. The value of harsh case, case 1 is selected the half of standard ramping rate.

Table 6 and Table 7 show daily operational cost obtained by each method and contribution rate (CR) of each method in comparison with local search. Here CR implies the relative cost reduction effect normalized by the result of LS. We selected the best value of objective function after parameter tuning. Moreover, number of iteration is empirically determined to be 500. It was the value enough to find the best value in all the cases. Figure 4(a), Figure 4(b) shows that the optimal operations obtained by each method in each case. In all the cases, gas boiler is not used in the best operations, which is attributed to the assumed scenario where hot water demands don't have rapid variations. Figure 4(a) shows that the operation planed by proposed method (MTS) avoids local optimal solutions; on the other hand, other methods misguide the operations into local optimal solutions.

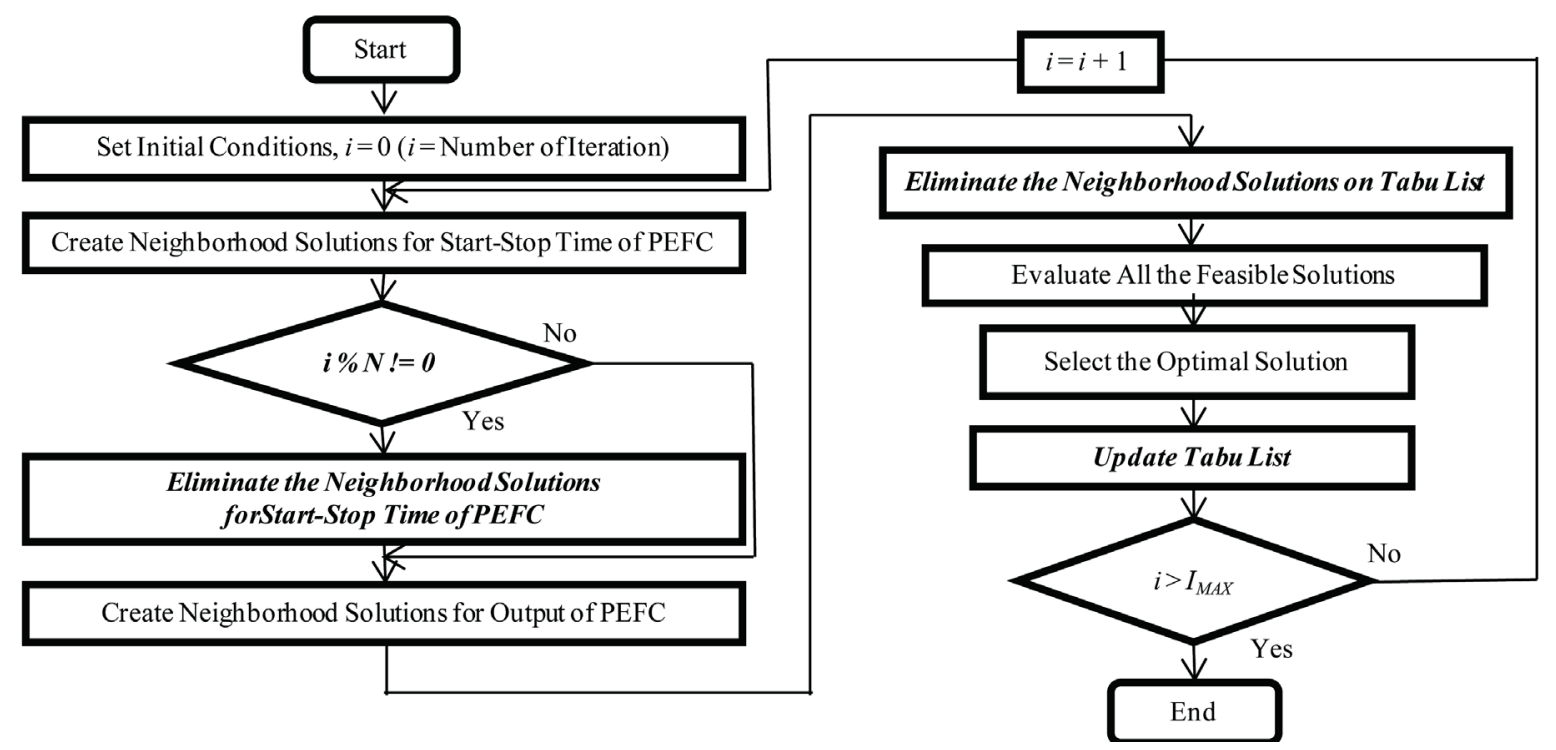

Figure 3. Flowchart of proposed method ( $N$ : Parameter [-], $I_{M A X}$ : Maximum number of iteration).

Table 4. Summation of electricity demand and hot water demand in each season.

\begin{tabular}{ccccccccccc}
\hline Hot Water Demand & \multicolumn{3}{c}{ Large } & \multicolumn{3}{c}{ Middle } & & \multicolumn{3}{c}{ Small } \\
\hline Season & Summer & $\begin{array}{c}\text { Middle } \\
\text { Season }\end{array}$ & Winter & Summer & Middle Season & Winter & Summer & $\begin{array}{c}\text { Middle } \\
\text { Season }\end{array}$ & Winter \\
\hline Electricity Demand [kWh] & 36.21 & 38.36 & 54.80 & 29.91 & 31.34 & 57.2 & 33.61 & 32.92 & 37.2 \\
Hot Water Demand [L] & 12.09 & 34.72 & 46.52 & 9.52 & 13.71 & 37.91 & 0.00 & 11.28 & 20.54 \\
\hline
\end{tabular}




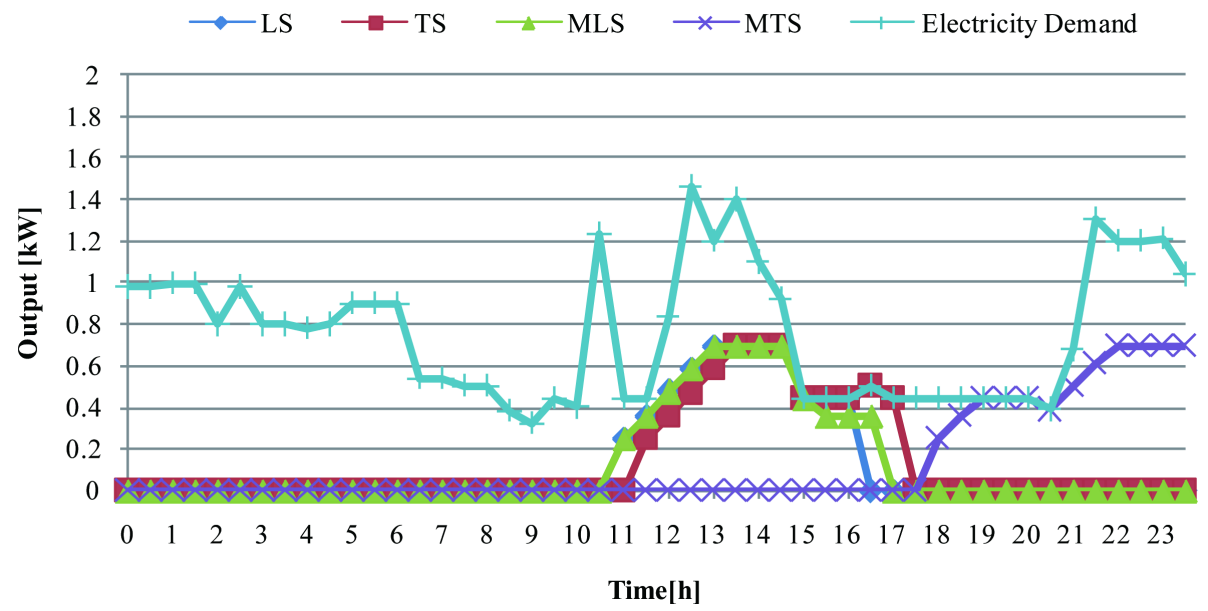

(a)

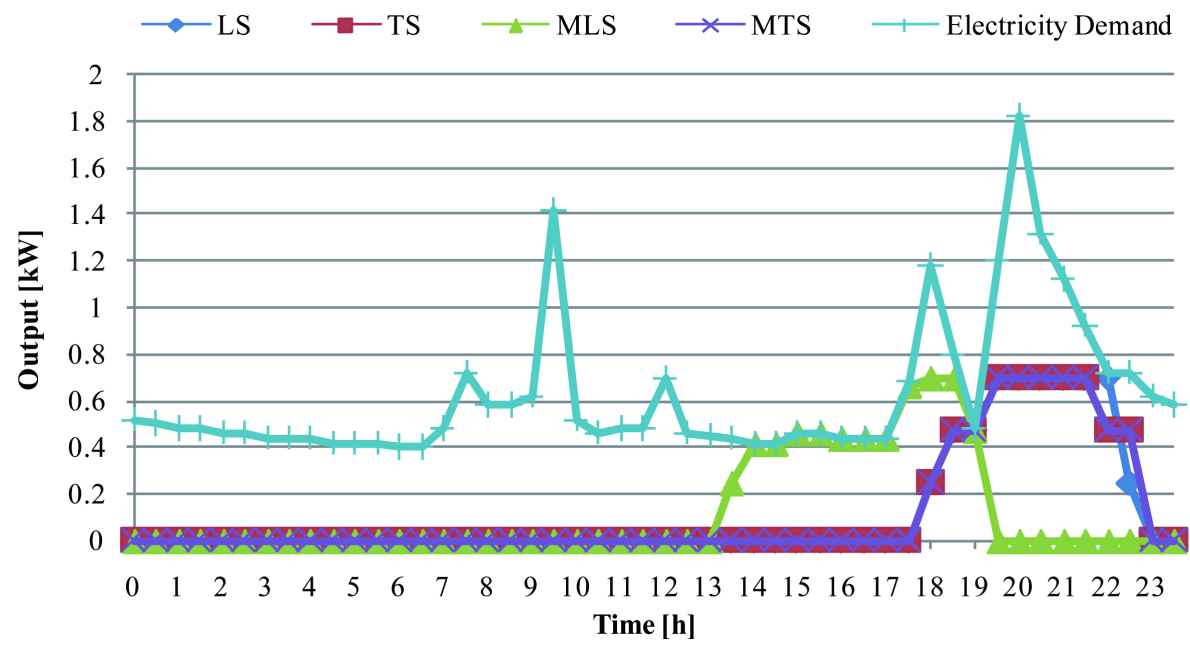

(b)

Figure 4. Optimal operations obtained by each method. (a) Case 1, Summer, (Large); (b) Case 2, Summer, (Middle).

Table 5. Assumed ramping rate constraints in each case.

\begin{tabular}{ccc}
\hline & $\Delta P_{\text {UP }}[\mathrm{kW} / 0.5 \mathrm{~h}]$ & $\Delta P_{\text {Down }}[\mathrm{kW} / 0.5 \mathrm{~h}]$ \\
\hline Case 1 (harsh case) & 0.1125 & 0.2250 \\
Case 2 [7] (standard case) & 0.2250 & 0.4500 \\
\hline
\end{tabular}

Table 6. Daily operational cost (DOC) obtained by each method and contribution rate (CR) of each method (Case 1).

\begin{tabular}{cccccccccc}
\hline Hot Water Demand & \multicolumn{3}{c}{ Large } & \multicolumn{3}{c}{ Middle } & \multicolumn{3}{c}{ Small } \\
\hline Season & Summer & Middle Season & Winter & Summer & Middle Season & Winter & Summer & Middle Season & Winter \\
\hline DOC (LS) [yen] & 504.05 & 532.66 & 760.89 & 417.14 & 430.87 & 795.29 & 469.30 & 455.07 & 514.08 \\
DOC (TS) [yen] & 504.52 & 524.84 & 752.44 & 413.80 & 427.01 & 787.32 & 466.83 & 450.17 & 506.43 \\
DOC (MLS) [yen] & 504.36 & 524.58 & 756.34 & 414.97 & 428.24 & 789.74 & 468.37 & 450.49 & 507.40 \\
DOC (MTS) [yen] & 503.78 & 524.53 & 752.74 & 413.76 & 427.01 & 787.01 & 466.88 & 450.17 & 506.38 \\
CR (TS) [\%] & -0.09 & 1.47 & 1.11 & 0.80 & 0.89 & 1.00 & 0.53 & 1.08 & 1.49 \\
CR (MLS) [\%] & -0.06 & 1.52 & 0.60 & 0.52 & 0.61 & 0.70 & 0.20 & 1.01 & 1.30 \\
CR (MTS) [\%] & 0.05 & 1.53 & 1.07 & 0.81 & 0.89 & 1.04 & 0.52 & 1.08 & 1.50 \\
\hline
\end{tabular}


Table 7. Daily operational Cost (DOC) Obtained by each method and contribution rate (CR) of each method (Case 2).

\begin{tabular}{cccccccccc}
\hline Hot Water Demand & \multicolumn{3}{c}{ Large } & \multicolumn{3}{c}{ Middle } & \multicolumn{3}{c}{ Small } \\
\hline Season & Summer & Middle Season & Winter & Summer & Middle Season & Winter & Summer & Middle Season & Winter \\
\hline DOC (LS) [yen] & 503.76 & 523.60 & 751.37 & 412.95 & 428.15 & 786.21 & 466.27 & 449.16 & 506.21 \\
DOC (TS) [yen] & 503.32 & 523.72 & 751.46 & 413.32 & 427.48 & 786.21 & 466.27 & 449.16 & 506.41 \\
DOC (MLS) [yen] & 503.76 & 530.82 & 752.67 & 416.10 & 430.87 & 786.10 & 468.83 & 455.04 & 506.25 \\
DOC (MTS) [yen] & 503.38 & 523.72 & 751.46 & 413.38 & 427.48 & 786.21 & 466.27 & 449.16 & 506.41 \\
CR (TS) [\%] & 0.09 & -0.02 & -0.01 & -0.09 & 0.16 & 0.00 & 0.00 & 0.00 & -0.04 \\
CR (MLS) [\%] & 0.00 & -1.38 & -0.17 & -0.76 & -0.63 & 0.01 & -0.55 & -1.31 & -0.01 \\
CR (MTS) [\%] & 0.09 & -0.02 & -0.01 & -0.09 & 0.16 & 0.00 & 0.00 & 0.00 & -0.04 \\
\hline
\end{tabular}

\section{Conclusions}

This paper proposes an optimal operation planning method based on tabu search for residential PEFC-CGS. From the simulation results of case 1 , the efficacy of MTS and tabu search was confirmed about 1 [\%]. In addition, the results of case 2 shows tabu search and MTS don't contribute to the reduction of daily operational cost in many conditions. This result attributes to the restriction of the search to avoid the trap into local optimal solutions. In case 2, the search along output power axis proceeds more easily in comparison with case1. Thus, it can be considered tabu search and proposed method adversely guide the search into local optimal solutions.

In this paper, we disregard hot water for disposal because on only daily operation planning is considered. However, disposal water is clearly wasteful for the operation. In near future, we plan to study the operation planning for residential PEFC-CGS considering hot water for disposal to plan more practically.

\section{References}

[1] The Japan Electrical Manufacture’s Association (JEMA) (2013) Investigative Report of Stationary Fuel Cell System’s Shipment and the Statistics. 62-65.

[2] Panasonic Corporation (2013) Press Release. http://news.panasonic.com/press/news/official.data/data.dir/2013/09/jn130910-3/jn130910-3.html

[3] Hayashi, Y., Kawasaki, S., Matsuki, J., Tomomoto, A., Miyamoto, H., Funabashi, T., Okuno, Y. and Hayashi, T. (2008) Determination Method of Optimal Operation Schedule for Fuel Cells in Collective Housing. IEEJ Transactions on Power and Energy, 128, 1217-1225. http://dx.doi.org/10.1541/ieejpes.128.1217

[4] Sugihara, H., Kato, T., Suzuki, Y. and Tsuji, K. (2004) A Daily Start and Stop Algorithm for Residential Fuel Cell Systems Considering Settings of Day-Ahead Hot Water Demand. IEEJ Transactions on Power and Energy, 124, 705713. http://dx.doi.org/10.1541/ieejpes.124.705

[5] Inui, Y., Muto, T. and Maeda, T. (2008) Study on Capacity and Operation Method of PEFC $\mu C G S$ for Apartment Using Measured Electricity and Hot Water Loads. IEEJ Transactions on Power and Energy, 128, 451-458. http://dx.doi.org/10.1541/ieejpes.128.451

[6] Fuel Cell Commercialization Conference of Japan (FCCJ) (2010) Objectives, R\&D Issues and Proposal of the Method of Evaluation for PEFC, 28.

[7] Maeda, K., Yonemori, H. and Yasaka, Y. (2011) An Estimation of Reduction of the Primary Energy and the $\mathrm{CO}_{2}$ Emission in Residential PEFC Co-Generation System with Li-Ion Battery Modules. IEEJ Transactions on Power and Energy, 131, 110. http://dx.doi.org/10.1541/ieejpes.131.108

[8] Kato, T., Hino, N., Kasugai, S. and Suzuoki, Y. (2003) Economic Assessment of Home Co-Generation System with PEFC Based on Survey of Hot-Water Demand. IEEJ Transactions on Power and Energy, 123, 1513-1520. http://dx.doi.org/10.1541/ieejpes.123.1513

[9] Japanese Government (2006) Enforcement Order Concerning Promotions of Plans for Global Warming.

[10] Central Environment Council (Japan) (2001) Interim Report for Subcommittee of the Achievement Scenarios of the Aims, Global Environment Section.

[11] Ministry of the Environment and Ministry of Economy, Trade, and Industry (2006) List of Calculation Method and 
Emission Factor Concerning Calculation, Report, and Announcement.

[12] Bureau of Waterworks Tokyo Metropolitan Government (2012) Home Page.

[13] Ministry of Environment (Japan) (2012) Tax for Plans of Global Warming.

[14] Glover, F. (1989) Tabu Search: Part 1. ORSA Journal on Computing, 1, 190-206. http://dx.doi.org/10.1287/ijoc.1.3.190

[15] Glover, F. (1990) Tabu Search: Part 2. ORSA Journal on Computing, 2, 4-32. http://dx.doi.org/10.1287/ijoc.2.1.4 